\title{
Seasonal changes in water quality and macrophytes and the impact of cattle on tropical floodplain waterholes
}

\author{
N.E. Pettit ${ }^{1}$, T.D. Jardine ${ }^{2}$, S. K. Hamilton ${ }^{3}$, V. Sinnamon ${ }^{4}$, D. Valdez ${ }^{2}$, P.M. Davies ${ }^{1}$, M.M.
} Douglas $^{5}$ and S.E. Bunn ${ }^{2}$

${ }^{1}$ Centre of Excellence in Natural Resource Management, Albany, University of Western Australia, Australia, ${ }^{2}$ Australian Rivers Institute, Griffith University, Nathan, Qld., Australia, ${ }^{3}$ Kellogg Biological Station and Department of Zoology, Michigan State University, Michigan, USA, ${ }^{4}$ Kowanyama Aboriginal Land and Natural Resource Management Office, Kowanyama, Qld., Australia, ${ }^{5}$ Charles Darwin University.

\begin{abstract}
This study indicates the critical role of hydrologic connectivity in floodplain waterholes in the wet-dry tropics of northern Australia. These waterbodies provide dry season refugia for plants and animals, are a hotspot of productivity, and are a critical part in the subsistence economy of many remote Aboriginal communities. We examined seasonal changes in water quality and aquatic plant cover of floodplain waterholes, and related changes to variation of waterhole depth and visitation by livestock. The waterholes showed declining water quality through the dry season which was exacerbated by more frequent cattle usage as conditions become progressively drier, which also increased turbidity and nutrient concentrations. Aquatic macrophyte biomass was highest in the early dry season, but biomass declined as the dry season progressed. Remaining macrophytes were flushed out by the first wet season flows although they quickly re-establish later during the wet season. Waterholes of greater depth were more resistant to the effects of cattle disturbance, and seasonal flushing of the waterholes with wet season flooding homogenized the water quality and increased plant cover of previously disparate waterholes. Therefore, maintaining high levels of connectivity between the river and its floodplain is vital for the persistence of these waterholes.
\end{abstract}

Keywords: macrophytes, water quality, seasonal waterbodies, lacustrine, floodplain 


\section{Introduction}

Freshwater bodies in seasonally inundated floodplains that retain water throughout the year in all but the driest years (relatively permanent) are highly productive ecosystems that function as important refugia for aquatic plants and animals during the dry season (Junk 1997; Bunn et al. 2005; Sheldon et al. 2010; Pettit et al. 2011a). Seasonal inundation and subsequent isolation are the primary drivers of ecological processes within these systems (Junk and Furch 1993; Finlayson 2005; Tockner et al. 2010; Warfe et al. 2011). In northern Australia, floodplain waterbodies are often called waterholes or billabongs, and can be the only fresh water that persists on the landscape over protracted dry seasons (Finlayson 2005). About 45 $\%$ of Australia's freshwater resources lie in tropical Australia and there is now an escalating focus on the management and development of river floodplain ecosystems in this region (Cresswell et al. 2009). Throughout this region waterholes are highly valued for ecosystem services ranging from the provision of plants and animals (e.g., fishes, turtles) to livestock water supply, to ecotourism (Jackson et al. 2005).

Ecological resilience is measured as the magnitude of disturbance that a system can absorb before it is restructured into another state often with different controlling variables and processes (Gunderson and Holling, 2002; Scheffer et al., 2003). Resilience therefore means that a system can undergo change after a disturbance to revert back to more or less the same stable state (Forman and Godron, 1981; Walker and Salt, 2006). Biological thresholds can be considered a 'tipping point' where the magnitude of the disturbance overcomes system resilience and it changes to an alternate state. Alternate states in shallow freshwater ecosystems have been widely reported in Europe and North America and occur for example, when a waterbody passes a threshold in water clarity that determines whether macrophytes or phytoplankton are competitively advantaged (Breukers et al., 1997; Scheffer et al., 2001; Scheffer and Carpenter, 2003; Scheffer and Jeppesen, 2007; Davis et al., 2010). In many floodplain landscapes, waterholes often change seasonally from a clear water phase dominated by submerged macrophytes to turbid systems dominated by phytoplankton, sometimes with lower oxygen and diminished biodiversity (Mitchell and Rogers 1985; Breukers et al. 1997; Scheffer and van Nes 2007; Ward et al. 2012).

Tropical floodplain rivers are found across northern Australia and support a diverse array of plants and animals (Finlayson, 2005). These floodplain rivers have a distinct seasonal flow 
regime, with most rainfall occurring between December and February (Leigh and Sheldon 2009) and most rivers retain their natural hydrological regime (Douglas et al. 2005). These rivers thus have strong connectivity with their floodplains (Jardine et al. 2012) and during high flows, water spreads across the floodplain inundating lacustrine and palustrine waterbodies (Ward et al. 2012), with variability of flows contributing to habitat diversity of over time (Warfe et al.2011). Whilst there is good information on the distribution patterns of the many permanent and semi-permanent waterholes and wetlands scattered across the region (Finlayson et al. 2006), very little is known of the ecology of these ecosystems, including the adaptations of the biota to seasonal fluctuations of wetting and drying as well as the importance of connectivity to the river.

The Mitchell River in tropical north Queensland, Australia, which contains a large number of permanent and ephemeral floodplain waterholes, across an area of $7150 \mathrm{~km}^{2}$ of the alluvial megafan (EPA 2005). Within the Mitchell River floodplain water quality and biodiversity of waterholes are under threat from cattle as well as feral pigs and horses (Kennard 2010). Many of these waterholes harbour locally threatened native plant species such as lotus (Nelumbo nucifera) and common reed (Phragmites australis) that have cultural values to Aboriginal inhabitants. These waterholes also provide important habitat for fishes, reptiles, waterbirds and other wildlife. Knowledge of the attributes of waterholes that confer stability and resilience is critically important in managing them, particularly in the face of possible combined stressors of invasive animals, invasive alien plants, water resource development, and climate change (Vorosmarty et al. 2010).

The aims of this study were to understand the effects of the seasonal hydrological cycle on water quality and aquatic plants in a set of waterholes on the Mitchell River floodplain in tropical northern Australia. We also examined the usage and effect of non-native large mammals on water quality and aquatic plant communities. We hypothesised that seasonal flooding, as well as particular physical attributes of the waterholes will provide some resilience to the interplay of seasonal drying and exogenous disturbances.

\section{Methods}

Study site 
This study was conducted on perennial palustrine waterholes on the floodplain of the Mitchell River in northern Queensland, Australia (Fig. 1). The climate in this region is tropical with a distinct wet season (November to May) and dry season, with long term average annual rainfall of about $970 \mathrm{~mm}(\mathrm{CV}=26 \%)$ of which $95 \%$ falls in the wet season, and a mean annual potential evapotranspiration of $1905 \mathrm{~mm}$ (Creswell et al. 2009). Rainfall during the study period (August 2009 to June 2010) indicated generally average conditions for the wet and dry seasons with a lack of any rain in October 2009 and a wetter than average January and April for the 2009/10 wet season (Fig. 2).

The Mitchell River is perennial (Kennard et al. 2010) and arises from the western slopes of the Great Dividing Range in eastern Queensland, and flows west for around $500 \mathrm{~km}$ to discharge into the Gulf of Carpentaria, 30km north-east of the community of Kowanyama (Fig. 1). Wet season high flows inundate at least some of the floodplain in most years but floods have a short residence time of around 1-3 months (Ward et al. 2012). The study area is part of the $7152 \mathrm{~km}^{2}$ Mitchell River fan aggregation which is listed in the directory of important wetlands in Australia (EPA 2005). This alluvial fan contains over 9,000 waterbodies ranging in size from many hectares to small shallow depressions and includes deeply incised stream lines with permanent waterholes, seasonally flooded back plains and numerous perennial and ephemeral depressions (CSIRO 2009). Soils are alluvial sands, silts and clays and vegetation is a grassy woodland savanna characterised by an overstorey including Eucalyptus microtheca and a ground-layer of grasses including Dichanthium spp. The waterholes are generally fringed with an area of riparian vegetation of varying density, including an overstorey of E. microtheca, Melaleuca spp., Excoecaria parvifolia, Corypha utan, with Barringtonia acutangula occurring on the wetter fringes, with a grass (e.g. Dichanthium spp.) and sedge (e.g. Cyperus spp., Eleocharis sp.) understorey. The Mitchell river catchment is very sparsely populated $\left(\sim 1\right.$ person per $\left.13 \mathrm{~km}^{2}\right)$ and the predominant landuse, cattle grazing on unimproved native pasture, occurs throughout the region (CSIRO 2009; Warfe et al. 2011). Large populations of feral pigs as well as some horses are common throughout the region (Mitchell River Watershed Management Group 2001).

\section{Sampling procedure}

Nine floodplain waterholes were selected for this study (Fig.1) and ranged in size from 0.7 to 5.7 ha. Sampling was sequential, following a dry season to wet season cycle (Fig. 2), with initial sampling in the mid-dry season (August 2009), further sampling done at the end of the 
dry season (October 2009) and a third sampling after the 2009/10 wet season, early in the following dry season (June 2010). To assess animal use at each waterhole a 100-m shoreline transect parallel to the water's edge (as it was at the time of sampling) was selected, with three 50-m perpendicular transects at 0,50 and $100 \mathrm{~m}$, extending into the fringing riparian vegetation. Animal prints (pugging) and waste (cowpats) were recorded along each of the four transects (within $1 \mathrm{~m}$ either side).

At the initial sampling time only (August 2009), riparian vegetation fringing each waterhole was surveyed along the three perpendicular transects at 0,25 and $50 \mathrm{~m}$ within a $5 \mathrm{x} 5 \mathrm{~m}$ quadrat. This gave a total of nine riparian quadrats at each site; three at the water's edge, three within the riparian zone, and three at or near the boundary with the terrestrial zone. All plant species within each quadrat were identified and a visual estimate made of projected foliage cover, of $\%$ litter and $\%$ bare earth. As an indicator of cattle usage of the riparian areas of the waterholes, the number of cow pats within each $5 \times 5 \mathrm{~m}$ quadrat, as well as along each transect, was recorded. Soil samples (top soil, $0-5 \mathrm{~cm}$ ) were also taken from each plot and analysed for organic carbon $(\mathrm{C})$, total nitrogen $(\mathrm{N})$ and total phosphorus $(\mathrm{P}, \mathrm{NaOH}$ extractable).

To measure aquatic vegetation within the waterhole, shorter $20 \mathrm{~m}$ long transects were extended out into the water at 0,50 and $100 \mathrm{~m}$ along the shoreline transect. Aquatic macrophyte species composition and \% cover were estimated within $1 \times 1 \mathrm{~m}$ quadrats at 0,5 , 10,15 and $20 \mathrm{~m}$ into the water along these three aquatic transects.

Within the approximate centre of each waterhole, a vertical profile of water quality measurements was taken from a boat using a Quanta Water Quality Monitoring System (Hydrolab, Austin, Texas) and included temperature $\left({ }^{\circ} \mathrm{C}\right)$, conductivity $\left(\mathrm{mS} \mathrm{cm}^{-1}\right), \mathrm{pH}$, turbidity (NTU), and dissolved oxygen (\%). Water samples were also stored on ice and frozen immediately to measure total $\mathrm{N}\left(\mathrm{mg} \mathrm{L}^{-1}\right)$ and total $\mathrm{P}\left(\mathrm{mgL}^{-1}\right)$ as well as filtered samples to measure dissolved $\mathrm{N}\left(\mathrm{NO}_{3}{ }^{-}+\mathrm{NO}_{2}{ }^{-}\right.$, hereafter referred to as $\mathrm{NO}_{\mathrm{x}}$ as well as $\mathrm{NH}_{4}{ }^{+}$ $\left.\left(\mathrm{mg} \mathrm{L}^{-1}\right)\right)$ and $\mathrm{PO}_{4}{ }^{3-}\left(\mathrm{mg} \mathrm{L}^{-1}\right)$ with detection limits of 0.04 and $0.01 \mathrm{mg} \mathrm{L}^{-1}$ for $\mathrm{TN}$ and $\mathrm{TP}$, respectively, and $0.001 \mathrm{mg} \mathrm{L}^{-1}$ for dissolved $\mathrm{N} \& \mathrm{P}$. Particulate material in suspension (seston) was collected on three GF/F glass-fibre filters, kept in the dark, frozen, and analysed for chlorophyll $a\left(\mu \mathrm{g} \mathrm{L}^{-1}\right)$. Nutrients and chlorophyll were analysed using standard colorimetric methods (APHA 1998). 
The use of waterholes by cattle, pigs and horses was monitored by time-lapse cameras (Moultrie Game Spy, EBSCO Industries, Inc., Alabaster, AL), mounted on riparian trees and set to automatically take a photograph of the waterhole edge every hour. These cameras were installed in August 2009 and photos retrieved in October 2009 and June 2010. Photographs from the time lapse camera were also used to estimate general changes in cover of macrophytes at each waterhole, with three of the authors (TJ, SK, NP) independently estimating total macrophyte cover from the photographs, at each waterhole for particular dates and time. These three estimates were in broad agreement (all $r>0.89 ; p<0.001$ ) and also showed a good relationship with cover measured along the transects on the three sampling dates $(r=0.83 ; \mathrm{p}<0.001)$. This gave us some confidence that cover estimates made from camera data reflected reasonably well the aquatic macrophyte cover at the waterholes. These averaged estimates of macrophyte \% cover taken from the waterhole photographs therefore complemented macrophyte cover measured along the transects at the three sampling times and provided a record of change in macrophyte cover throughout the nine months of the study that could not be achieved from measures taken only at the three sampling times.

\section{Data analysis}

All data used in statistical tests were tested for normality and transformed $(\log (x+1))$ where necessary. Plant community data for aquatic vegetation were analysed using non-parametric routines in PRIMER Version 6.1.5 (Clarke and Gorley 2006) and the PERMANOVA+ software addition (Anderson et al. 2008). Species diversity (Shannon-Wiener index (H)) and richness was measured using the DIVERSE routine in PRIMER. To test for differences in aquatic plant communities among waterholes and sampling times, the permutational multivariate analysis (PERMANOVA) technique was employed using Bray Curtis similarity. A similarity percentages (SIMPER) routine was performed to identify which plant species contributed most to the average dissimilarity among different waterholes and sampling times. To explore which group of environmental variables best explained the variation observed in aquatic plant community data, the distance based linear models (DistLM) routine in PERMANOVA (Legendre and Anderson 1999) was used. A Bray-Curtis similarity matrix of the plant community data was used for this analysis, and a step-wise selection of transformed $(\log (\mathrm{x}+1))$ environmental variables (\%litter, \% bare ground, abundance cattle dung, soil total 
$\mathrm{N}$, total $\mathrm{P}$ and $\mathrm{C}, \mathrm{C}: \mathrm{N}$ and \% canopy cover) was conducted using the adjusted $\mathrm{R}^{2}$ selection criterion and a permutation test of significance (Legendre and Anderson 1999).

Overall water quality differences between the waterholes for the 11 environmental variables measured (Secchi depth, maximum depth, surface $\mathrm{pH}$, conductivity, dissolved oxygen, turbidity, total $\mathrm{N}$, total $\mathrm{P}, \mathrm{NH}_{4}{ }^{+}, \mathrm{NO}_{\mathrm{x}}$ and $\mathrm{PO}_{4}{ }^{3-}$ ), was visually assessed using principal components analysis (PCA) after data were transformed $(\log (x+1)$ and normalised (subtract mean and divide by standard deviation, Clarke and Gorley 2006). Differences in water quality data between waterholes and seasons was analyzed using analysis of similarities (ANOSIM; Clarke and Gorley 2006). The relationship between maximum depth and turbidity and nutrients as well between nutrients and chlorophylla for the waterholes, over each sampling time was analysed using Pearson correlation coefficient (Clarke and Gorley 2006). Relationships were also examined between cattle numbers and waterhole water quality variables. Cattle density was evaluated using daily counts of cattle from the time-lapse cameras.

\section{Results}

\section{Waterhole plants}

There were no differences in aquatic plant community composition at the nine waterholes between sampling times ( $\mathrm{pseudoF}_{2,20}=1.23, \mathrm{p}=0.277$ ). There was also no significant difference in species richness $\left(\mathrm{pseudoF}_{2,20}=1.81, \mathrm{p}=0.171\right)$ or diversity $(\mathrm{H})\left(\right.$ pseudoF $_{2,20}=$ $1.16, \mathrm{p}=0.352$ ) of aquatic plants between sampling times. Rather, differences between sampling times were mainly related to changes in biomass (and discussed in the following section). There was some seasonal change in certain species with the water lilies Nymphaea violacea and Nymphoides indica only prominent at Crayfish, Turrum, Maggie Hole and Surprise Yards waterholes in the mid-dry (August 2009) and early-dry samplings (June 2010, Table 1). Fishhole Creek waterhole was dissimilar from the other waterholes with the dominance of the floating exotic Eichhornia crassipes year round. T submerged aquatic Ceratophyllum demersum was the most prominent macrophyte at waterholes with higher levels of water clarity including Pirrial, Duckhole, Red Lily and Maggie Hole, while at the more turbid waterholes, Turrum and Magker, the best indicator was the semi-aquatic 
riparian/emergent Ludwigia ascendens which grows on the waterhole margins and extends out into the water when levels are high.

Water quality variables that were significantly related to the aquatic macrophyte species composition were conductivity $\left(\mathrm{pseudoF}_{1,21}=3.86, \mathrm{p}=0.004\right)$ and total $\mathrm{P}\left(\mathrm{pseudoF}_{1,21}=\right.$ $1.94, \mathrm{p}=0.04)$. Sites with generally high conductivity were Pirrial and Duckhole in August and October where the most dominant plants were the submerged $C$. demersum and the floating fern Azolla filiculoides. At Fishole creek where the floating exotic E. crassipes was dominant conductivity and total $\mathrm{P}$ was much lower than at the other sites (Tables $1 \& 2$ ).

Cover of aquatic macrophytes varied considerably among waterholes on a given sampling date as well as within waterholes throughout the year (Fig. 3). For example, at Duckhole macrophyte cover was $80-90 \%$ for most of the dry season, predominantly the floating fern $A$. filiculoides and the submerged $C$. demersum (Table 1), while there were virtually no macrophytes during the dry season at Turrum, Surprise Yards and Maguera waterholes (Table 1, Fig. 3). With the initial inundation of the waterholes in the early to mid-wet season, there was a dramatic reduction in cover at Duckhole of what is most likely to be the floating A. filiculoides as it is pushed or blown to the edges of the waterhole. Following the flood, there was a quick response of plants, with cover of the macrophytes increasing rapidly in most waterholes (Fig. 3).

There were large changes in the appearance and character of the waterholes as the season progressed (Fig. 4). In the mid-dry season (August 09), water levels were still reasonably high and there was aquatic vegetation visible across most of the waterholes (Figs. 4a, d). At the end of the dry season (October 09), water levels were very low and the water was usually highly turbid. There were large areas of exposed bank, aquatic vegetation was sparse and there were extensive areas of animal disturbance (cattle, horses and feral pigs) within and surrounding the waterhole (Fig. $4 \mathrm{~b}, \mathrm{e}$ ). At the end of the wet season water levels were at their highest and water was less turbid, and there was generally a prolific growth of macrophytes within the waterholes (Fig. 4c, f). The riparian areas surrounding the waterholes were also affected by cattle as measured by the frequency of cow pats within plots. Higher cow pat numbers correlated with reduced total riparian plant cover $(r=-0.56, p<0.01)$ and an increase in soil $\% \mathrm{~N}(\mathrm{r}=0.47, \mathrm{p}<0.02)$ and $\% \mathrm{C}(\mathrm{r}=0.46, \mathrm{p}<0.05)$. 


\section{Changes in water quality}

Environmental conditions within the waterholes changed considerably over the three sampling times. There were significant differences in water quality between sampling times $(\mathrm{R}=0.187, \mathrm{p}=0.002$ ) with differences between August 09(early dry)- and October 2009 (late dry, $\mathrm{R}=0.359, \mathrm{p}=0.001$ ), and between June10 (early dry) and October 09 (late dry, $\mathrm{R}=$ 0.193, $\mathrm{p}=0.024$ ), but not between June 10 (early dry) and August 09 (mid dry) sampling times $(\mathrm{R}=0.025, \mathrm{p}=0.257)$. Differences in water quality between sites showed the waterholes Makger, Surprise Yards, Crayfish Hole and Turrum diverged strongly from the other sites late in the dry season but all sites were similar by the early dry season sampling in June 2010 (Table 2, Fig. 5). This was mostly related to water depth, conductivity and nutrients, along PC1 (explaining 56\% of variation), while $\mathrm{pH}$ and dissolved oxygen were important for the separation of sites along PC2 (19.5\% of the variation, Fig 5). The water quality variables which were most responsible for differences between waterholes in the mid- and early-dry sampling times were $\mathrm{PO}_{4}, \mathrm{DO}, \mathrm{pH}$ and Secchi depth, while at the late-dry sampling time $\mathrm{NO}_{\mathrm{x}}, \mathrm{NH}_{4}$ and $\mathrm{pH}$ were most important.

\section{Drivers of water quality changes in waterholes}

There was a wide range in water depth across the waterholes (Table 2) and some of the variation in water quality can be explained by differences in water depth (Fig. 6). Over the study period, maximum water depth decreased as the dry season progressed from the mid-dry season (August 2009) to the late dry season (October 09), while turbidity, conductivity, nutrients and sestonic chlorophyll $a$ increased (Table 2). For all waterholes in the mid and late dry seasons, nutrients (total P and total $\mathrm{N}$ ) and turbidity were negatively correlated with water depth (all $\mathrm{r}>-0.31, \mathrm{p}<0.1$ ), while turbidity was positively correlated with nutrients ( total $\mathrm{P}$ and total $\mathrm{N}$ ) and total $\mathrm{N}$ was positively correlated with chlorophyll $a$ (all $\mathrm{r}>0.63, \mathrm{p}<$ 0.05); Table 2, Fig. 6). These relationships were strongest in the late dry season (October 2009) but had broken down and were not significant by the next early dry season (June 2010) sampling, which followed the wet season flooding (all $r<0.28, \mathrm{p}>0.1$, Table 2, Fig. 6).

Cattle numbers identified from cameras set up at each waterhole indicated that the number visiting the water increased substantially as the dry season progressed (Fig. 7a). Numbers decreased quickly once wet season rains began in early November (Fig. 7a). At the site level, the number of cattle utilizing waterholes was positively correlated with an increase in water total $\mathrm{N}(\mathrm{r}=0.516, \mathrm{p}<0.02)$ and total $\mathrm{P}(\mathrm{r}=0.617, \mathrm{p}<0.005)$ in both early and late dry 
season samples (Fig. 7b). In the late dry season, cattle numbers were positively correlated with water column chlorophyll $a$ levels $(r=0.571, \mathrm{p}<0.05$, Fig. $7 \mathrm{~b})$ and negatively correlated with light penetration $(r=0.819, p<0.001$, Fig. $7 d)$.

\section{Discussion}

The waterholes examined in this study are subject to seasonal inundation, which may last only a few weeks or longer and occur in one or several episodes (Ward et al. 2012). The waterholes subsequently experience a protracted dry season during the rest of the year, in which they often decrease considerably in depth and area, creating stressful conditions for aquatic biota (Pettit et al. 2011b; Warfe et al. 2011). Our results from these tropical Australian floodplain waterholes have parallels to those reported for shallow floodplain waterbodies elsewhere in Australia as well as in South America, with floods resetting waterbodies so that they become biophysically very similar by the end of the wet season but then diverging strongly during the dry season (Lewis et al. 2000; Thomaz et al. 2007; Roozen et al. 2008; Davies et al. 2008; Sheldon and Fellows 2010). Hydrologic connectivity has consistently been found to be a critical driver of water quality and aquatic community assemblages in floodplain waterholes, despite wide variation in climate (Mitchell and Rogers 1985; Gallerdo et al. 2009).

The waterholes surveyed in this study show some resilience to the seasonal cycle of drying and flooding, which sees them undergo significant changes throughout the year as they become more dissimilar under drying conditions (Fig. 8). With the onset of the wet season, after the initial inundation phase, water quality improves, turbidity decreases and macrophytes re-establish so that waterholes return to a similar functioning state at the end of this seasonal cycle (Fig. 8). The predictability in the timing and amplitude of seasonal flooding is important in the development of these adaptations in waterhole biota (Junk and Furch 1993). However some variability in flows is important in maintaining resilience by maintaining a range of biological and physical characteristics that interact with life history traits of the biota (Naiman et al. 2008; Davies 2010). This variation in the physical environment such as shape and depth of waterholes and the type and extent of fringing vegetation will also contribute to resilience in that there is a diversity of biophysical ecosystem functions (Colloff and Baldwin 2010). 
Disturbances other than the natural flood regime are likely to test the resilience of these waterholes and possibly lead to a change of state (Fig. 8). This change may come about through stressors that are beyond the natural disturbance regime, such as when livestock grazing is introduced. However, given the natural variation of waterholes on floodplains, some are likely to be more resistant to these changes than others. For example, our study indicated the deeper waterholes were more resistant to the effects of increased disturbance from cattle and feral animal use, particularly in the late-dry season. Shallow waterholes are more susceptible to high turbidity due to wind-derived re-suspension of sediments which can be exacerbated by cattle disturbance which have greater access to these shallow waterholes. Therefore in shallow waterholes greater seasonal flushing is required to return the system to similar conditions to the pre-dry season state (Fig. 8). How an ecosystem re-establishes after disturbance is not assured (Holling and Gunderson 2002) and divergence from the previous state is most likely after a subsequent disturbance which may result in the establishment of a different but relatively stable state, such as one adapted to more xeric conditions and with greater livestock and feral animal disturbance (Fig. 8).

Cattle numbers visiting the waterholes increased significantly as the dry season progressed, but visits quickly diminished after significant rains made water readily available throughout the floodplain. Other studies have shown similar seasonal waterhole use by large herbivores (Armour et al. 1994; James et al. 1999; Thrash 2000) and pigs (Caley 1997; Bowman and McDonough 1991). Although we measured no direct effects, cattle grazing on aquatic macrophytes were observed, which given the large numbers by the end of the dry season, is likely to have a substantial effect on macrophyte biomass. Increasing cattle numbers may also explain the increase in total $\mathrm{N}$ and $\mathrm{P}$ levels, not only in the water but also the surrounding riparian zone. This increase in nutrient levels may lead to the eutrophication of the waterhole resulting in algal blooms and a reduction in water quality. . Cattle trampling in the littoral zone can also inhibit the re-establishment of macrophytes and destroy the band of benthic algae which can be a critical carbon source for the aquatic food webs in waterholes (Bunn et al. 2003; 2005).

Our results indicate that to some extent these effects of cattle and other feral animals on the waterholes are obscured by seasonal flooding, which effectively resets the system (Fig. 8). Similar conclusions were made for the effects of pigs on other waterholes in north-east 
Queensland (Doupé et al. 2010). However cattle and other feral animals using waterholes may have more detrimental long-term effects such as eliminating susceptible plant species and providing enhanced dispersal opportunities for aquatic invasive plants by carrying propagules to and from waterholes in mud or faeces. Feral pigs may also have more direct impacts through consuming buried plant rhizomes and tubers as well as predating on turtles and mussels aestivating in the mud, which become accessible as the waterholes dry out at the end of the dry season (Fordham et. al. 2008; V. Sinnamon pers. obs.).

After the initial inundation of the waterholes at the beginning of the wet season remaining macrophytes may be flushed out of the waterholes, but recovery is rapid as macrophytes resprout from tubers and rhizomes or seed as flow subsides and high, clear water conditions are conducive to aquatic plant growth. These seasonal flow dynamics are an important driver of waterhole macrophytes which has been reported also for shallow floodplain lakes in Europe (van Geest et al. 2007), South Africa (Mitchell and Rogers 1985) and South America (Welcomme 1985; Loverde-Oliveira et al. 2009). The magnitude and duration of flooding are also likely to be important as flows of sufficient size and duration are required to change water chemistry, replenish nutrients and allow germination or resprouting and growth of aquatic plants (Davies et al. 2008). Small magnitude, short duration floods were shown to be inadequate to stimulate macrophyte production in floodplain waterbodies on the Parana River in South America (Carignan and Neiff 1992).

Differences in aquatic plant composition seen among waterholes were related to particular conditions within waterholes. This is also indicated by the lack of seasonal differences in species richness or composition for waterholes, as the initial waterhole environment determines aquatic macrophyte composition (Rolon et al. 2008). In this study the amphibious plants that are well adapted to seasonal wetting and drying cycles such as the perennial grass Pseudoraphis spinescens and the perennial herbs Ludwigia adscendens and Persicaria spp. were associated with waterholes that undergo significant drying and increased turbidity. These life forms are likely to become more prevalent if there is a trend of increased drying for these waterholes. The biggest difference in macrophyte community composition in the present study was seen at Fishhole Creek waterhole, with the dominance of the floating exotic herb Eichhornia crassipes, which resulted in this waterhole having the lowest species richness and diversity. This plant is native to South American floodplains and grows and reproduces very rapidly, quickly occupying all available space (Neiff et al. 2008). . E. 
crassipes is a weed of national significance in Australia and poses a major threat to wetlands throughout tropical northern Australia (http://www.weeds.org.au/WoNS/waterhyacinth/, accessed 24/7/12).

Floodplain waterholes in the wet-dry tropics of northern Australia play a crucial role in the river-floodplain ecosystem (Finlayson 2005; Pettit et al. 2011a), and our results show the critical role of hydrologic connectivity in their maintenance. Exogenous disturbances such as cattle and feral animals, as well as the invasion of exotic plants, are largely intractable and ongoing management problems that clearly have negative effects on the floodplain waterhole ecosystem. Alterations to the wet season hydrology of these floodplain rivers, either anthropogenic or climate-induced, may compound the effects of these exogenous disturbances and reduce the resilience of these ecosystems (Finlayson et al. 2005). Limiting cattle use of waterholes is generally not feasible nor, in economic terms, is it desirable, except in particular cases such as for protecting waterholes of cultural or ecological significance. Our study re-enforces the importance of maintaining flow connectivity between these floodplain waterholes and the river together with sufficient variability in the flow regime (Naiman et al. 2008, Opperman et al. 2010) to allow the seasonal resetting of conditions, to maintain waterhole resilience.

\section{Acknowledgements}

The authors gratefully acknowledge the Kowanyama Aboriginal Land and Natural Resource Management Office, for assistance with site selection and field data collection. We thank Dr Danielle Warfe (CDU) and Professor Bob Naiman (UW) for helpful comments on the manuscript. Funding for this project was provided by the Tropical Rivers and Coastal Knowledge (TRaCK) research programme which receives major funding for its research through the Australian Government's Commonwealth Environment Research Facilities initiative, the Australian Government's Raising National Water Standards Programme, the Fisheries Research and Development Corporation, and the Queensland Government's Smart State Innovation Fund.

\section{References}


Anderson, M.J., Gorley, R.N., and Clarke, K.R. (2008). 'PERMANOVA+ for PRIMER: Guide 25 to Software and Statistical Methods.' (PRIMER-E., Plymouth, UK.)

Armour, C., Duff, D., and Elmore, W. (1994). The effects of livestock grazing on western riparian and stream ecosystem. Fisheries 19, 9-12.

APHA .(1998). Standard Methods for the examination of water and wastewater. Washington, American Public Health Association, American Water Works Association, Water Environment Federation.

Bowman, D.M.J.S., and McDonough, L. (1991). Feral pig (Sus scrofa) rooting in a monsoon forest-wetland transition, northern Australia. Wildlife Research 18, 761-765.

Breukers, C.P.M., van Dam, E.M., and Sjoerdtje, A. (1997). Lake Volkerak-Zoom: a lake shifting from the clear to the turbid state. Hydrobiologia 342/343, 367-376.

Bunn, S.E., Davies, P.M., and Winning, M. (2003). Sources of organic carbon supporting the food web of an arid zone floodplain river. Freshwater Biology 48, 619-635.

Bunn, S.E., Balcombe, S.R., Davies, P.M., Fellows, C.S., and McKenzie-Smith, F.J. (2005). Aquatic productivity and food webs of desert river ecosystems. In 'Changeable, Changed, Changing: the ecology of desert rivers,' (Ed R. Kingsford) pp 76-99. (Cambridge University Press: Cambridge, UK.)

Caley, P. (1997). Movements, activity patterns and habitat use of feral pigs (Sus scrofa) in a tropical habitat. Wildlife Research 24, 77-87.

Carignan, R., and Neiff, J. (1992). Nutrient dynamics in the floodplain ponds of the Parana River (Argentina) dominated by water hyacinth Eichhornia crassipes. Biogeochemistry 17, 85-121.

Clarke, K.R., and Gorley, R.N. (2006). 'PRIMER v6: user manual/tutorial.' (Primer-E., Plymouth, UK.)

Colloff, M.J., and Baldwin, D.S. (2010). Resilience of floodplain ecosystems in a semi-arid environment. The Rangeland Journal 32, 305-314.

Cresswell, R., Petheram, C., Harrington, G., Buettikofer, H., Hodgen, M., et al. (2009). 'Water resources in northern Australia.' In 'Northern Australia Land and Water Science Review'. (Ed P. Stone P), Final Report to the Northern Australia Land and Water Taskforce, CSIRO, Canberra, Australia.

CSIRO. (2009). Water in Northern Australia. Summary of Reports to the Australian Government from the CSIRO Northern Australia Sustainable Yields Project, Commonwealth Scientific and Industrial Research Organisation, Canberra, Australia.

Davies, P.M. (2010). Climate change implications for river restoration in global biodiversity hotspots. Restoration Ecology 18, 261-268.

Davies, P.M., Bunn, S.E., Hamilton, S.K. (2008). Primary production in tropical streams and rivers. In 'Tropical Stream Ecology'. (Ed D. Dudgeon), Chapter 2, pp. 23-42. (Elsevier London, U.K.)

Davis, J., Sim, L., and Chambers, J. (2010). Multiple stressors and regime shifts in shallow aquatic ecosystems in antipodean landscapes. Freshwater Biology 55, 5-18.

Douglas, M.M., Bunn, S.E., and Davies, P.M. (2005). River and wetland food webs in Australia's wet-dry tropics: general principles and implications for management. Marine and Freshwater Research 56, 329-342.

Doupé, R.G., Mitchell, J., Knott, M.J., Davis. A.M., and Lymbery, A.J. (2010). Efficacy of exclusion fencing to protect ephemeral floodplain lagoon habitats from feral pigs (Sus scrofa). Wetlands Ecology and Management 18, 69-78.

EPA. (2005) Wetland Mapping and Classification Methodology - Overall Framework - A Method to Provide Baseline Mapping and Classification for Wetlands in Queensland, Queensland Government., Brisbane, Australia. 
Finlayson, C.M. (2005). Plant ecology of Australia's tropical floodplain wetlands: A review. Annals of Botany 96, 541-555.

Finlayson, C.M., Bellio, M.G. and Lowry, J.B. (2005) A conceptual basis for the wise use of wetlands in northern Australia - linking information needs, integrated analyses, drivers of change and human well-being. Marine and Freshwater Research 56, 269-277.

Finlayson, C.M., Lowry, J., Bellio, M.G., Nou, S., Pidgeon, R., et al. (2006). Biodiversity of the wetlands of the Kakadu region, northern Australia. Aquatic Science 68, 374-399.

Fordham, D.A., Georges, A., and Brook, B.W. (2008). Indigenous harvest, exotic pig predation and local persistence of a long-lived vertebrate: managing a tropical freshwater turtle for sustainability and conservation. Journal of Applied Ecology 45, 52-62.

Forman RTT, Godron M. 1981. Patches and structural components for a landscape ecology. Bioscience 31: 733-739.

Gallerdo, B., Gascon, S., Gonzalez-Sanchis, M., Cabezas, A., and Comin, F.A. (2009). Modelling the response of floodplain aquatic assemblages across the lateral hydrological connectivity gradient. Marine and Freshwater Research 60, 924-935.

Gunderson LH, Holling CS. (eds) 2002. Panarchy: understanding transformations in human and natural systems. Island Press, Washington DC, USA.

Holling, C.S., and Gunderson, L.H. (2002). Resilience and adaptive cycles. In 'Panarchy.' (Eds L.H. Gunderson and C.S. Holling) pp. 293-313, (Island Press, Washington DC, USA.)

Jackson, S., Storrs, M., and Morrison J. (2005). Recognition of Aboriginal rights, interests and values in river research and management: perspectives from northern Australia. Ecological Management and Restoration 6, 105-110.

James, C.D., Landsberg, J., and Morton, S.R. (1999). Provision of watering points in the Australian arid zone: a review of effects on biota. Journal of Arid Environments 41, 87121.

Jardine T.D., Pusey B.J., Hamilton S.K., Pettit N.E., Davies P.M., Douglas M.M., Sinnamon V., Halliday I.A. and Bunn S.E. (2012) Fish mediate high food web connectivity in the lower reaches of a tropical floodplain river. Oecologia 168, 829-838.

Junk, W.J. (1997). Structure and function of the large central Amazonian River floodplains: Synthesis and discussion. In 'The Central Amazon Basin: Ecology of a pulsing basin.' (Ed. W.J. Junk), pp. 455-473. (Springer, Berlin, Germany.)

Junk, W.J., and Furch, K. (1993). A general review of tropical South American floodplains. Wetlands Ecology and Management 2, 231-238.

Kennard, M.J. (2010). 'Northern Australia trial of the draft High Conservation Value Aquatic Ecosystems (HCVAE) Framework.' Final Report to the Department of Environment, Water, Heritage and the Arts and the National Water Commission., Charles Darwin University., Darwin, Australia.

Kennard, M.J., Pusey, B.J., Olden, J.D., Mackay, S., Stein, J., et al. (2010). Classification of natural flow regimes in Australia to support environmental flow management. Freshwater Biology 55, 171-193.

Legendre, P., and Anderson, M.J. (1999). Distance-based redundancy analysis: testing multispecies responses in multifactorial ecological experiments. Ecological Monographs 69, 1-24.

Leigh, C., and Sheldon, F. (2009). Hydrological connectivity drives patterns of macroinvertebrate biodiversity in floodplain rivers of the Australian wet/dry tropics. Freshwater Biology 54, 549-571.

Lewis, W.M., Hamilton, S.K., Lasi, M.A., Rodriguez, M., and Saunders, J.F. (2000). Ecological determinism on the Orinoco Floodplain. Bioscience 50, 681-692. 
Loverde-Oliveira, S.M., Huszar, V.L.M., Mazzeo, N., and Scheffer, M. (2009). Hydrologydriven regime shifts in a shallow tropical lake. Ecosystems 12, 807-819.

Mitchell River Watershed Management Group. (2001). 'Mitchell River Watershed Management Plan', Department of Natural Resources, Mareeba, Queensland, Australia.

Mitchell, D.S., and Rogers, K.H. (1985). Seasonality/aseasonality of aquatic macrophytes in Southern Hemisphere inland waters. Hydrobiologia 125, 137-150.

Naiman, R.J., Latterell, J.J., Pettit, N.E., and Olden, J.D. (2008).Flow variability and the biophysical vitality of river systems. Comptes Rendus Geosciences 340, 629-643.

Neiff, J.J., Casco, S.L., and de Neiff, A.P. (2008). Response of Eichhornia crassipes (Pontederiaceae) to water level fluctuations in two lakes with different connectivity in the Parana River floodplain. International Journal of Tropical Biology 56, 613-623.

Opperman, J.J., Luster, R., McKenney, B.A., Roberts, M., and Meadows, A.W. (2010). Ecologically functional floodplains: connectivity, flow regime and scale. Journal of the American Water Resources Association 46, 211-226.

Pettit, N.E., Bayliss, P., Davies, P.M., Hamilton, S.K., Warfe, D.M., et al. (2011a). Seasonal contrasts in carbon resources and ecological processes on a tropical floodplain. Freshwater Biology 56, 1047-1064.

Pettit, N.E., Townsend, S.A., Dixon, I.H., and Wilson, D. (2011b) Plant communities of aquatic and riverine habitats. In 'Aquatic Biodiversity in Northern Australia' (Ed. B.J.Pusey) Chp 4, pp 37-50, (Charles Darwin University Press, Darwin, Australia).

Rolon, A.S., Lacerda, T., Maltchik, L., and Guadagnin, D.L. (2008). Influence of area, habitat and water chemistry on richness and composition of macrophyte assemblages in southern Brazilian wetlands. Journal of Vegetation Science 19, 221-228.

Roozen, F.C.J.M., Peeters E.T.H.M., Roijackers, R., Wyngaert, I.V.D., Wolters, H., et al. (2008). Fast response of lake plankton and nutrients to river inundations on floodplain lakes. River Research and Applications 24, 388-406.

Scheffer M, Carpenter SR, Foley JA, Folke C, Walker B. (2001). Catastrophic shifts in ecosystems. Nature 413: 591-596.

Scheffer M, Carpenter SR. (2003). Catastrophic regime shifts in ecosystems: linking theory to observation. Trends in Ecology and Evolution 18: 648-656.

Scheffer M, Jeppesen E. (2007). Regime shifts in shallow lakes. Ecosystems 10: 1-3.

Scheffer, M., and van Nes, E.H. (2007). Shallow lakes theory revisited: various alternative regimes driven by climate, nutrients, depth and lake size. Hydrobiologia 584, 455-466.

Scheffer M, Szabo S. Gragnani A, van Nes EH, Rinaldi S, Kautsky N, Norberg J, Roijackers RMM, Franken RJM. (2003). Floating plant dominance as a stable state. Proceedings of the National Academy of Science of the United States of America 100: 4040-4045.

Sheldon, F., and Fellows, C.S. (2010). Water quality in two Australian dryland rivers: spatial and temporal variability and the role of flow. Marine and Freshwater Research 61, 864874.

Sheldon, F., Bunn, S.E., Hughes, J.M., Arthington, A.H., Balcombe, S.R., et al. (2010). Dryland river waterholes: Ecological roles and threats to aquatic refugia in arid landscapes. Marine and Freshwater Research 61, 885-895.

Thomaz, S.M., Bini, L.M., and Bozelli, R.L. (2007). Floods increase similarity among aquatic habitats in river-floodplain systems. Hydrobiologia 579, 1-13.

Thrash, I. (2000). Determinants of the extent of indigenous large herbivore impact on herbaceous vegetation at watering points in the north-eastern lowveld, South Africa. Journal of Arid Environments 44, 61-72.

Tockner, K., Pusch, M., Borchardt, D., and Lorang, M.S. (2010). Multiple stressors in coupled river-floodplain ecosystems. Freshwater Biology 55 (Suppl. 1), 135-151. 
van Geest, G.J., Coops, H., Scheffer, M., and van Nes, E.H. (2007). Long transients near the ghost of a stable state in eutrophic shallow lakes with fluctuating water levels. Ecosystems 10, 36-46.

Vorosmarty, C.J., McIntyre, P.B., Gessner, M.O., Dudgeon, D., Prusevich, A., et al. (2010). Global threats to human water security and river biodiversity. Nature 467, 555-561.

Walker B, Salt D. 2006. Resilience thinking: Sustaining ecosystems and people in a changing world. Island Press, Washington, DC, USA.

Ward, D.P., Hamilton, S.K., Jardine, T.D., Pettit, N.E., Tews, E.K., et al. (2012) Assessing the seasonal dynamics of floodplain inundation, turbidity and aquatic vegetation in the Australian wet-dry tropics using optical remote sensing. Ecohydrology (on line) DOI: 10.1002/eco.1270.

Warfe, D.M., Pettit, N.E., Davies, P.M., Pusey, B.J., Hamilton, S.K., et al. (2011) The "wetdry" in the wet-dry tropics drives ecosystem structure and function of northern Australian rivers. Freshwater Biology 56, 2169-95.

Welcomme, R.L. (1985). 'River fisheries'. FAO Fisheries Technical Paper 262, 330 pp.. Rome, Italy. 


\section{List of Figures}

Figure 1: Location of the nine waterholes on the Mitchell River floodplain in north Queensland, Australia.

Figure 2: Monthly rainfall for the period of the study compared to the long-term average rainfall at the Kowanyama, within $30 \mathrm{~km}$ of the study sites. Sampling times were (1) the middry season (August 2009), (2) the late-dry season (October 2009), and (3) the end of wet season (June 2010).

Figure 3: Changes in aquatic plant cover on eight waterholes over the study period, from the mid-dry season (August 2009) to mid-wet season (February 2010). Cover was estimated from time-lapse cameras. Arrows indicate approximate date when each waterhole filled with flood water during the wet season (Mag = Magker; $\mathrm{CH}=$ Crayfish Hole; $\mathrm{FH}=$ Fish Hole $\mathrm{CK}$; SY $=$ Surprise Yards; Tur $=$ Turrum; RL $=$ Red Lily; DH $=$ Duckhole .

Figure 4: Change in appearance of two representative waterholes from the mid-dry season (August 2009) to late-dry season (October 2009) and mid-wet season (February 2010).

Figure 5: PCA ordination of waterhole environmental variables for the mid-dry season (August 2009), the late-dry season (October 2009), and the end of wet season (June 2010) sampling dates. Vector plot indicates environmental variables with $r^{2}>0.35$ for each axis. Site abbreviations are: Mak = Magker; $\mathrm{SY}=$ Surprise Yards; $\mathrm{RL}=$ Red Lily; $\mathrm{CH}=$ Crayfish Hole $; \mathrm{FC}=$ Fishhole $\mathrm{Ck} ; \mathrm{MH}=$ Maggie Hole; Pir $=$ Pirrial; Tur $=$ Turrum; $\mathrm{DH}=$ Duckhole. Environmental variables are: $\mathrm{pH} ; \mathrm{DO}=$ Dissolved oxygen; $\mathrm{TN}=$ water total nitrogen; $\mathrm{TP}=$ water total phosphorus; Turb = turbidity at the water surface; Cond $=$ conductivity at the water surface; Depth = maximum depth; Secchi $=$ Secchi depth.

Figure 6: Relationships for the nine waterholes in August 2009,October 2009 and June 2010 between maximum water depth and water total $\mathrm{P}, \mathrm{N}$ and turbidity $(\mathrm{a}, \mathrm{b}, \mathrm{c})$; turbidity and total $\mathrm{P}$ and $\mathrm{N}(\mathrm{d}, \mathrm{e})$; and between total $\mathrm{N}$ and chlorophyll $a(\mathrm{f})$. An $\mathrm{r}^{2}$ value and trend line is only presented for significant $(\mathrm{p}<0.05)$ relationships.

Figure 7: Association of cattle numbers with waterhole characteristics. a) increasing cattle numbers over the dry season (with 2 day moving average). Relationship between cattle numbers and b) water total $\mathrm{N}$ and $\mathrm{P}$; c) sestonic chlorophyll $a$; d) Secchi depth. All relationships are significant at $\mathrm{p}<0.01$.

Figure 8: Conceptual model of waterhole resilience to seasonal changes and the crucial role of wet season inflows. Shallow waterholes undergo greater changes during dry season drought, which is exacerbated by cattle disturbance. However the resetting effects of wet season flooding restores the shallow waterholes by the end of the wet season to conditions similar to those in deeper waterholes. 
Table 1: Changes in average vegetation cover $(\%)$ of the six most common aquatic macrophytes in waterholes over the study period, including $1=$ mid-dry season (August 2009), 2 = late dry season (October 2009) and 3 = early dry season (June 2010).

\begin{tabular}{|c|c|c|c|c|c|c|c|c|c|c|c|c|c|c|c|c|c|c|c|c|c|c|c|c|c|c|c|}
\hline \multirow{2}{*}{$\begin{array}{l}\text { Waterhole } \\
\text { Sampling date }\end{array}$} & \multicolumn{3}{|c|}{ Crayfish } & \multicolumn{3}{|c|}{ Duckhole } & \multicolumn{3}{|c|}{ Fishhole } & \multicolumn{3}{|c|}{ Maggie } & \multicolumn{3}{|c|}{ Magker } & \multicolumn{3}{|c|}{ Pirrial } & \multicolumn{3}{|c|}{ Red Lily } & \multicolumn{3}{|c|}{ Surprise } & \multicolumn{3}{|c|}{ Turrum } \\
\hline & 1 & 2 & 3 & 1 & 2 & 3 & 1 & 2 & 3 & 1 & 2 & 3 & 1 & 3 & 3 & 1 & 2 & 3 & 1 & 2 & 3 & 1 & 2 & 3 & 1 & 2 & 3 \\
\hline \multicolumn{28}{|l|}{ Species } \\
\hline Azolla filiculoides & & & & 82 & 88 & 1.7 & & & & 0.4 & 4.5 & 2.5 & 0.1 & & & 0.2 & & 3.2 & 4.6 & & & & & & 0.1 & & \\
\hline Pseudoraphis spinescens & & & 4.7 & & & 0.7 & & & & 2.3 & & 3.7 & 0.2 & & 0.1 & & & & 17 & 0.2 & 44 & & & 0.1 & 0.7 & & 4 \\
\hline Utricularia gibba & & & & 1 & & 2.7 & & & & 19 & 1.7 & 4 & 2.4 & & 21 & & & & 0.2 & 0.4 & 6 & & & & 15 & & 8.7 \\
\hline Ludwigia ascedens & & & & 1.1 & 0.3 & 15 & & & & 0.1 & 0.1 & 0.1 & 18 & 0.3 & 6.7 & & & 0.3 & 0.3 & & 8 & & & & 11 & & 16 \\
\hline Ceratophyllum demersum & & & & 77 & 32 & 31 & & & & 0.3 & 6.5 & 28 & & & & 53 & 37 & 51 & 3 & 51 & 20 & & & & & & \\
\hline Persicaria attenuata & & & & & & & & & & & & & & & & & & & 2.8 & 0.4 & 3 & & & & & & \\
\hline Nymphoides indica & 30 & & 22 & & & & & & & 9 & 0.1 & 2.3 & & & & & & & & & & & & & 0.2 & & 6.7 \\
\hline Nymphoides aurantiaca & 6.3 & & 7 & & & & & & & & & & 1.1 & & 0.9 & & & & 6.1 & 1.9 & 3.4 & & & & & & \\
\hline Nymphaea violacea & & & 0.3 & 4.4 & 0.7 & 11 & & & & & & 36 & & & 10 & 0.6 & & & & & 5 & & & 5 & & & 2 \\
\hline Marsilea $s p$ & & & & & & & & & & 0.6 & & 0.1 & & & & & & & & & & & & & & & \\
\hline Aponogeton sp & 0.2 & & & & & & & & & & & & & & & & & & & & & & & & & & \\
\hline Lemna aequinoctialis & & & & & & 0.2 & & & & & 24 & & 0.9 & & & & & 0.1 & & & & & & & 1.2 & & \\
\hline Eichhornia crassipes & & & & & & & 25 & 11 & 100 & & & & & & & & & & & & & & & & & & \\
\hline Nitella $s p$ & 29 & & & & & & 3.9 & 0.1 & & & & & & & & & & & 5.6 & & & & & & & & \\
\hline Oryza sp & & & 2 & & & 0.3 & & & & & & 5.3 & & & & & & & & & 2 & & & & & & 1 \\
\hline Caldesia acanthocarpa & & & & & & & & & & & & & & & & & & & & & 1 & & & & & & 2.7 \\
\hline Cyperus sp & & & 2 & & & & 0.1 & 0.5 & & & & & & & & & & & & & & & & & & & \\
\hline Cyanotis axillaris & & & & & & & & & & & & 0.1 & & & 1.7 & & & & & & & & & & & & \\
\hline Bacopa floribunda & & & & & & & & & & & & & & & & & & & & & & & & 0.1 & & & \\
\hline Total Cover & 66 & 0 & 39 & 166 & 121 & 63 & 29 & 11.5 & 100 & 32 & 37 & 82 & 23 & 0.3 & 40 & 54 & 37 & 55 & 40 & 54 & 92 & 0 & 0 & 5.1 & 28 & 0 & 41 \\
\hline Total Spp & 4 & 0 & 7 & 4 & 4 & 8 & 3 & 3 & 1 & 7 & 6 & 10 & 6 & 1 & 6 & 3 & 1 & 4 & 8 & 5 & 9 & 0 & 0 & 3 & 6 & 0 & 7 \\
\hline
\end{tabular}


Table 2: Changes in water quality and chlorophyll $a$ in waterholes over the study period, including mid-dry season (August 2009), late dry season (October 2009) and early dry season (June 2010).

\begin{tabular}{|c|c|c|c|c|c|c|c|c|c|c|c|c|c|c|c|c|c|c|c|}
\hline \multirow[b]{2}{*}{ waterhole } & \multirow{2}{*}{$\begin{array}{l}\text { Area } \\
\text { (ha) }\end{array}$} & \multicolumn{3}{|c|}{ Max. Depth (cm) } & \multicolumn{3}{|c|}{ Turbidity (NTU) } & \multicolumn{3}{|c|}{ Cond $(\mathrm{ms} / \mathrm{cm})$} & \multicolumn{3}{|c|}{ Total P (mg/L) } & \multicolumn{3}{|c|}{ Total N (mg/L) } & \multicolumn{3}{|c|}{ Chlorophyll $a(\mu \mathrm{g} / \mathrm{L})$} \\
\hline & & Aug09 & Oct09 & Jun10 & Aug09 & Oct09 & Jun10 & Aug09 & Oct09 & Jun10 & Aug09 & Oct09 & Jun10 & Aug09 & Oct09 & Jun10 & Aug09 & Oct09 & Jun10 \\
\hline Red Lilly & 5.7 & 190 & 140 & 160 & 3.3 & 45 & 1.8 & 0.06 & 0.14 & 0.04 & 0.16 & 0.18 & 0.05 & 0.78 & 1.80 & 0.59 & 4.41 & 27.11 & 69.77 \\
\hline Pirrial & 2.4 & 190 & 110 & 200 & 18.4 & 9 & 9.4 & 0.27 & 0.37 & 0.10 & 0.03 & 0.03 & 0.06 & 0.76 & 0.95 & 0.67 & 9.80 & 10.08 & 33.95 \\
\hline Maggie Hole & 1.1 & 130 & 80 & 180 & 48.3 & 2000 & 6.6 & 0.07 & 0.11 & 0.05 & 0.09 & 1.50 & 0.15 & 0.74 & 5.30 & 0.44 & 7.51 & 26.14 & 2.94 \\
\hline Crayfish Hole & 4.7 & 65 & 20 & 120 & 30.7 & 2000 & 23.4 & 0.12 & 0.29 & 0.04 & 0.08 & 3.60 & 0.07 & 0.81 & 16.00 & 0.46 & 9.02 & 166.62 & 5.58 \\
\hline Duckhole & 0.7 & 110 & 70 & 170 & 19.2 & 241 & 4.2 & 0.08 & 0.36 & 0.09 & 0.11 & 0.43 & 0.08 & 0.85 & 3.80 & 0.67 & 9.80 & 113.69 & 15.41 \\
\hline Surprise Yards & 1.3 & 80 & 9 & 130 & 150 & 971 & 28.1 & 0.09 & 0.34 & 0.06 & 0.36 & 1.10 & 0.06 & 3.60 & 21.00 & 0.75 & 137.40 & 520.84 & 22.11 \\
\hline Fishhole Ck & 1.6 & 180 & 100 & 230 & 15.9 & 20 & 265 & 0.02 & 0.02 & 0.04 & 0.03 & 0.05 & 0.08 & 0.45 & 0.69 & 0.75 & 4.32 & 17.25 & 8.82 \\
\hline Turrum & 2.5 & 100 & 50 & 170 & 300 & 2000 & 8.8 & 0.05 & 0.11 & 0.07 & 0.40 & 2.70 & 0.13 & 2.30 & 10.00 & 0.13 & 69.83 & 84.94 & 15.80 \\
\hline median & 2.1 & 110 & 70 & 170 & 30.7 & 971 & 9.4 & 0.07 & 0.14 & 0.06 & 0.11 & 1.10 & 0.07 & 0.81 & 5.30 & 0.67 & 9.02 & 78.41 & 15.80 \\
\hline
\end{tabular}




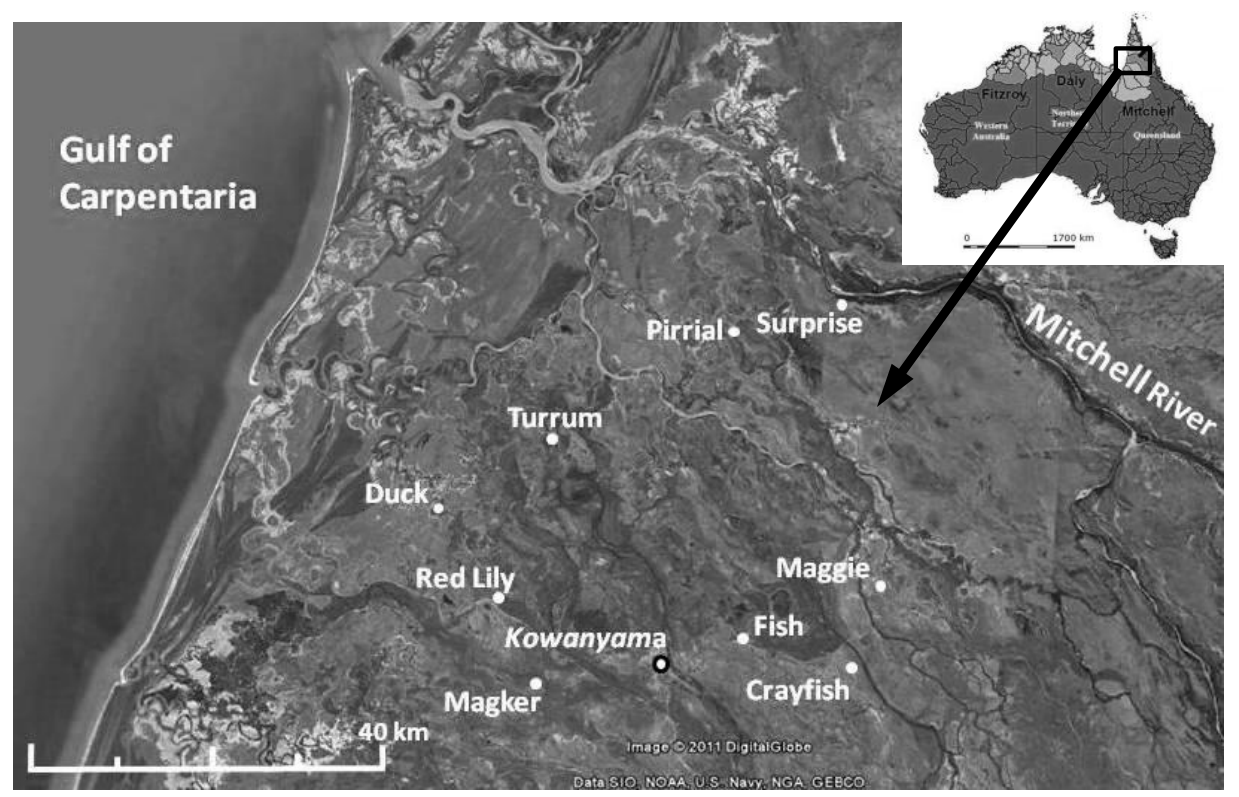

Figure 1:

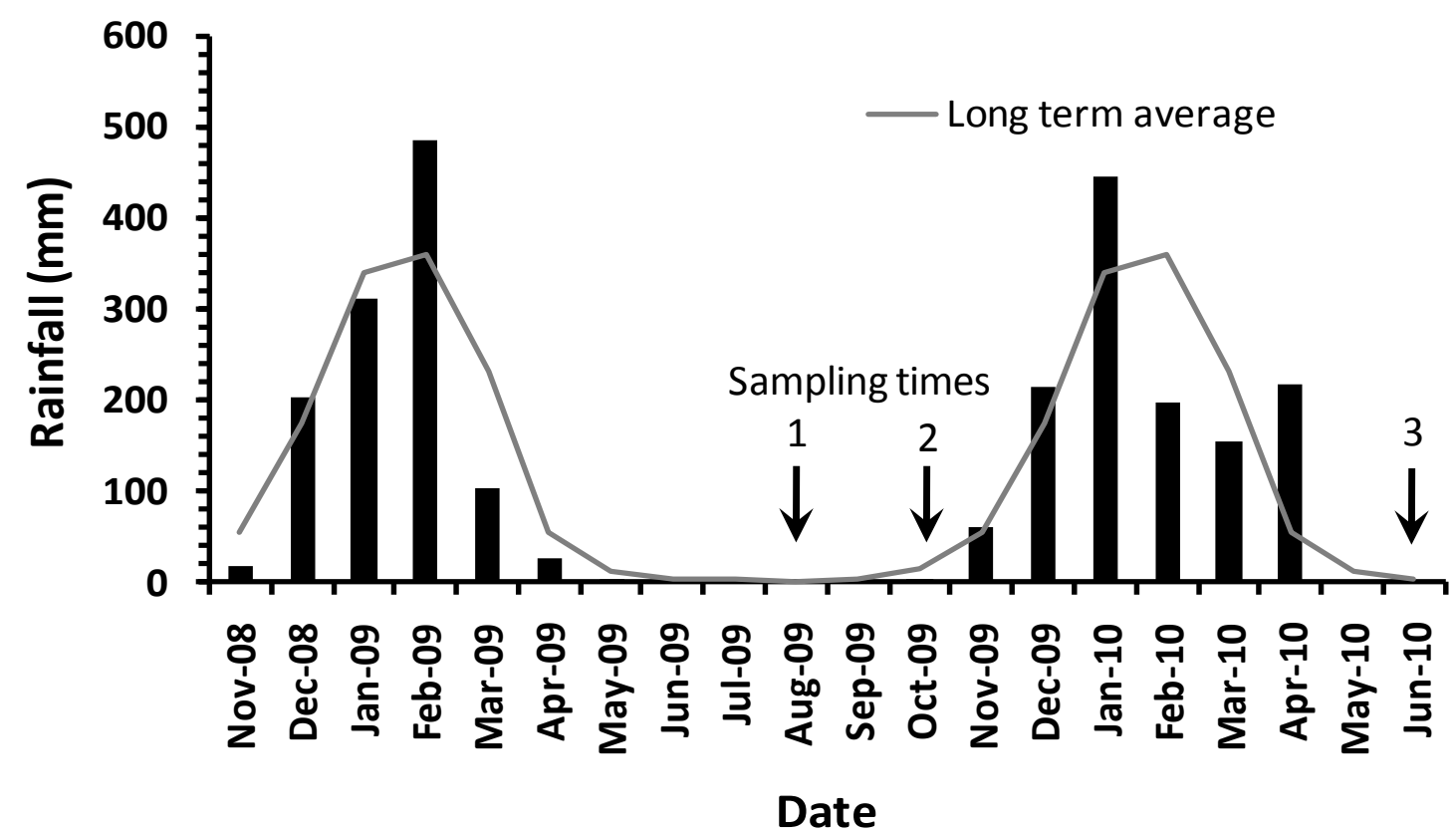

Figure 2: 


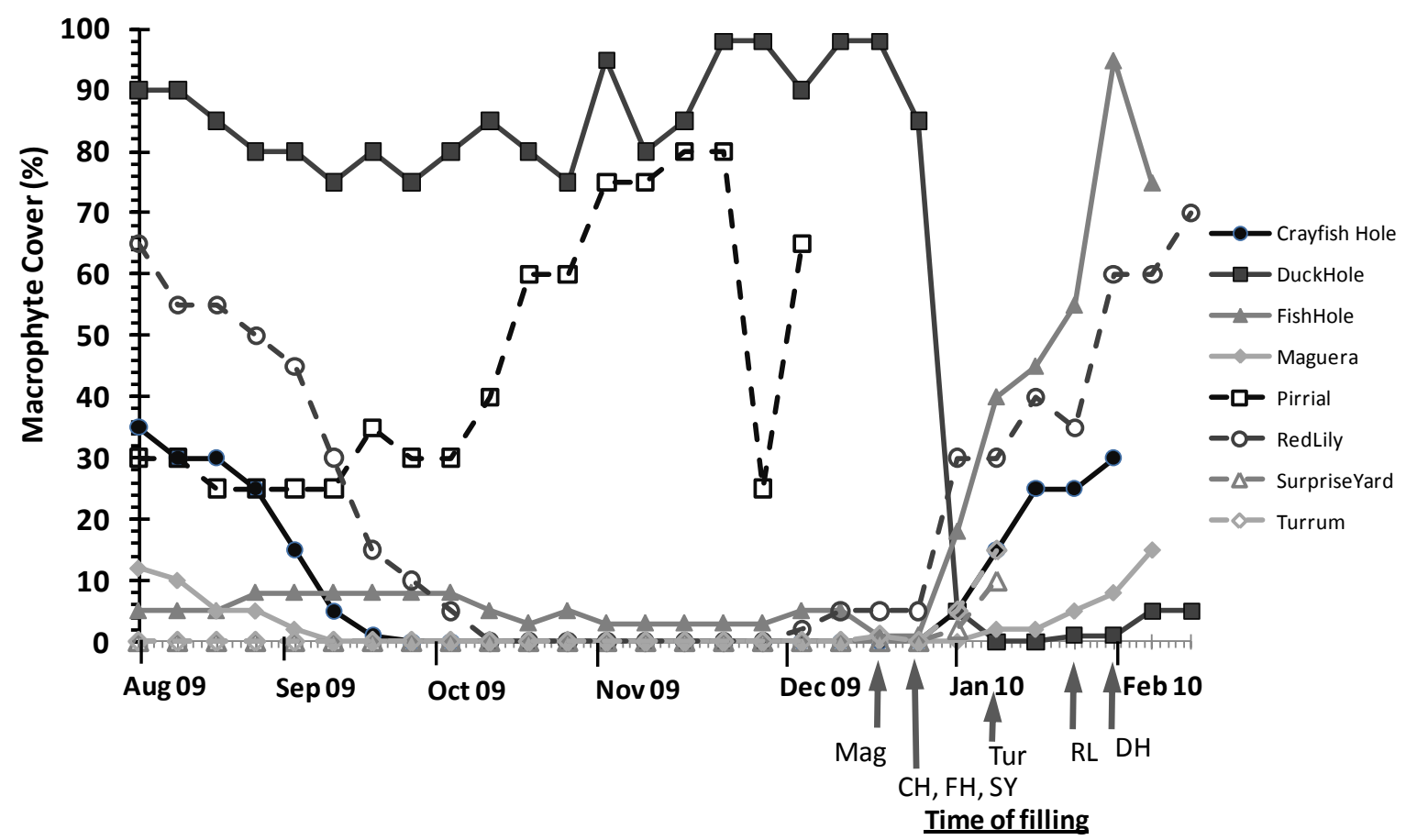

Figure 3: 

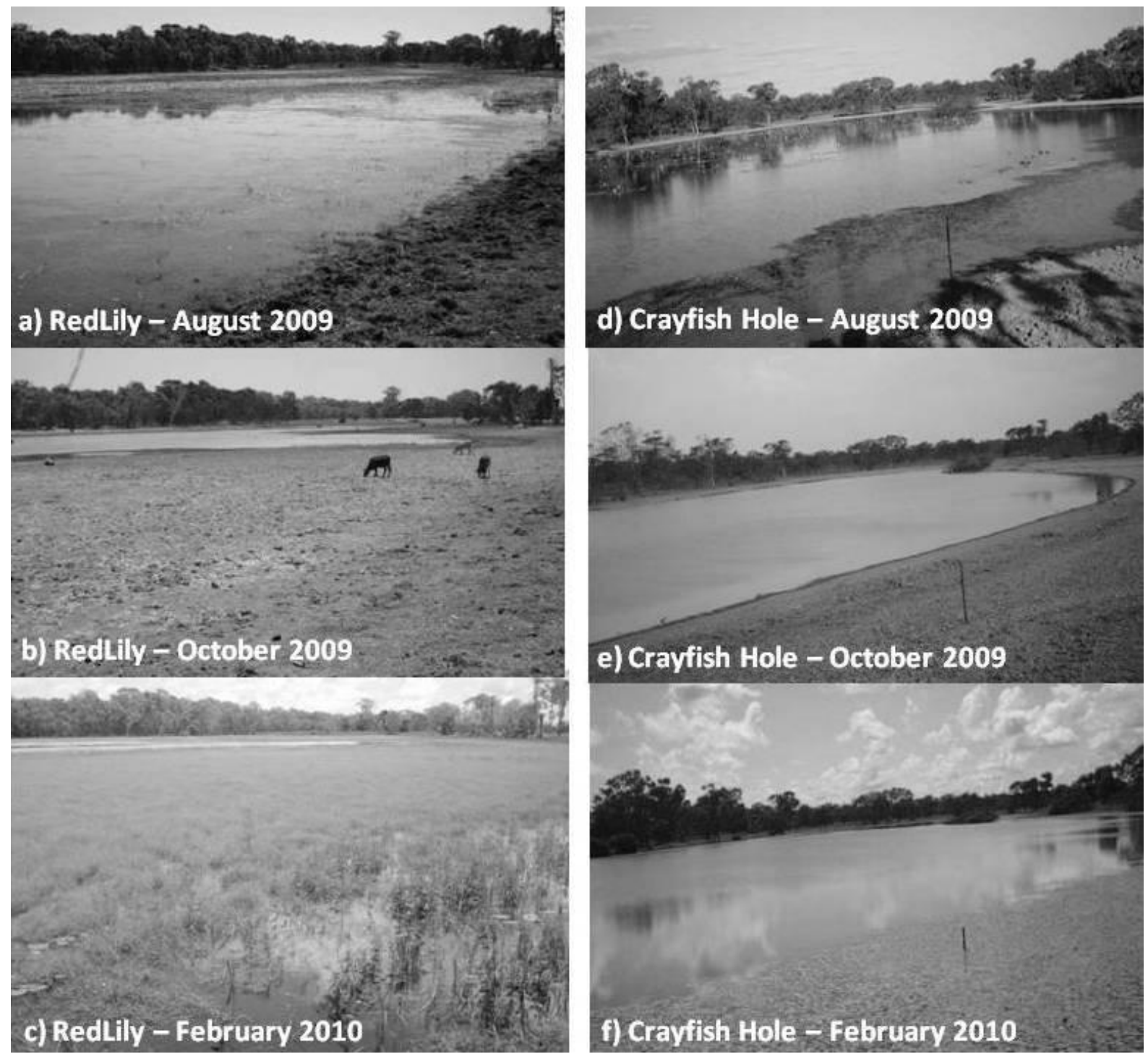

Figure 4: 


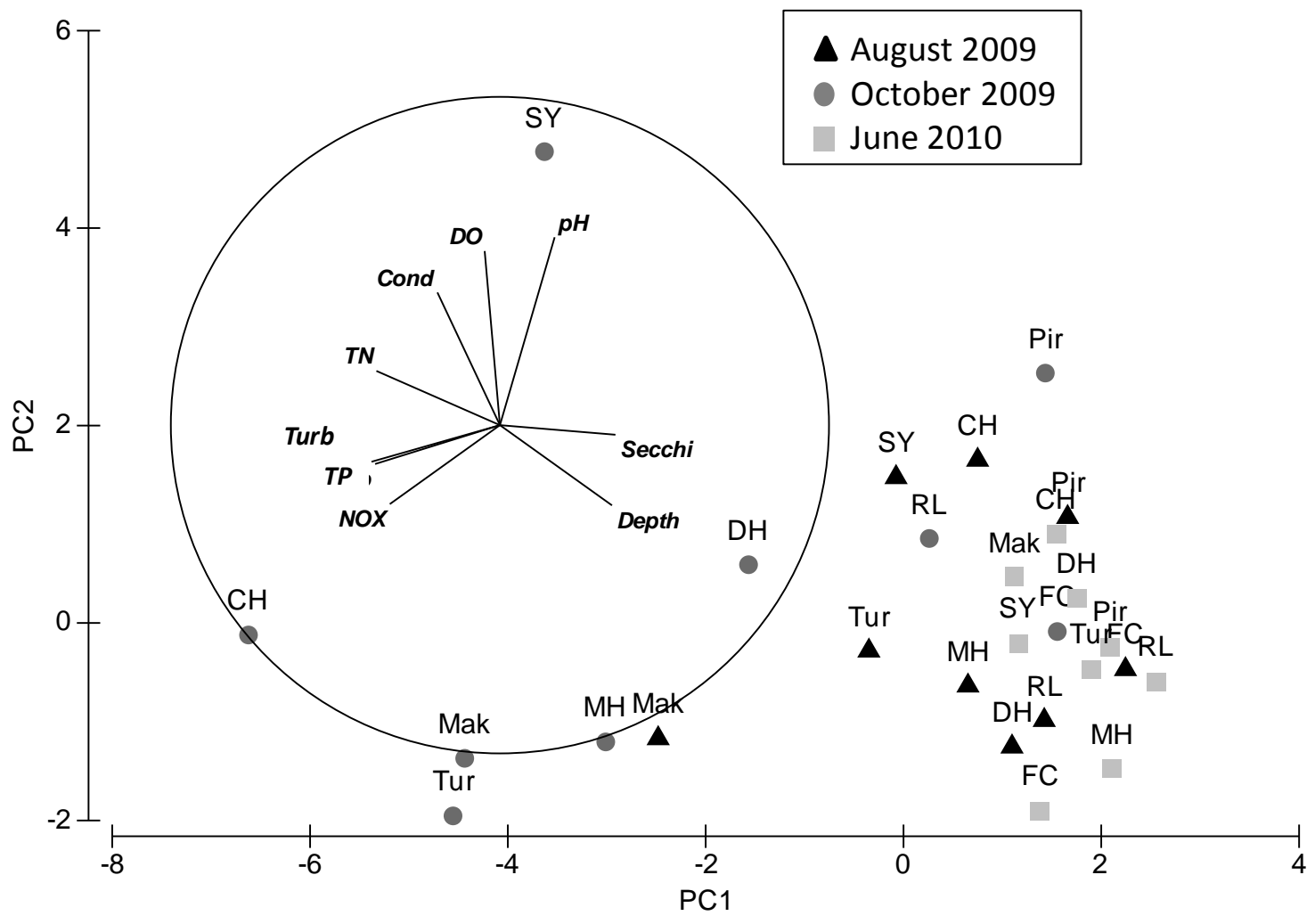

Figure 5: 

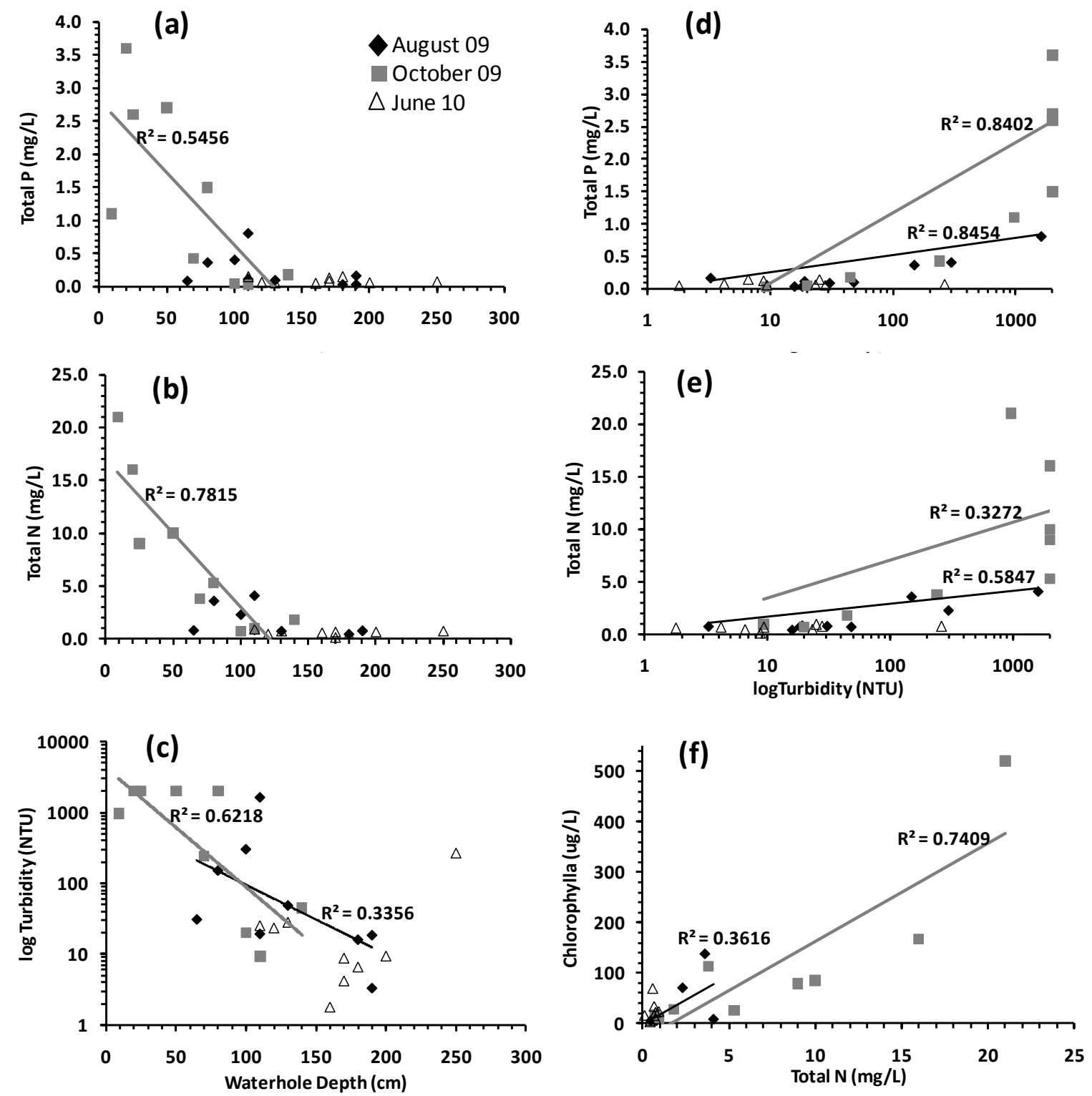

Figure 6: 

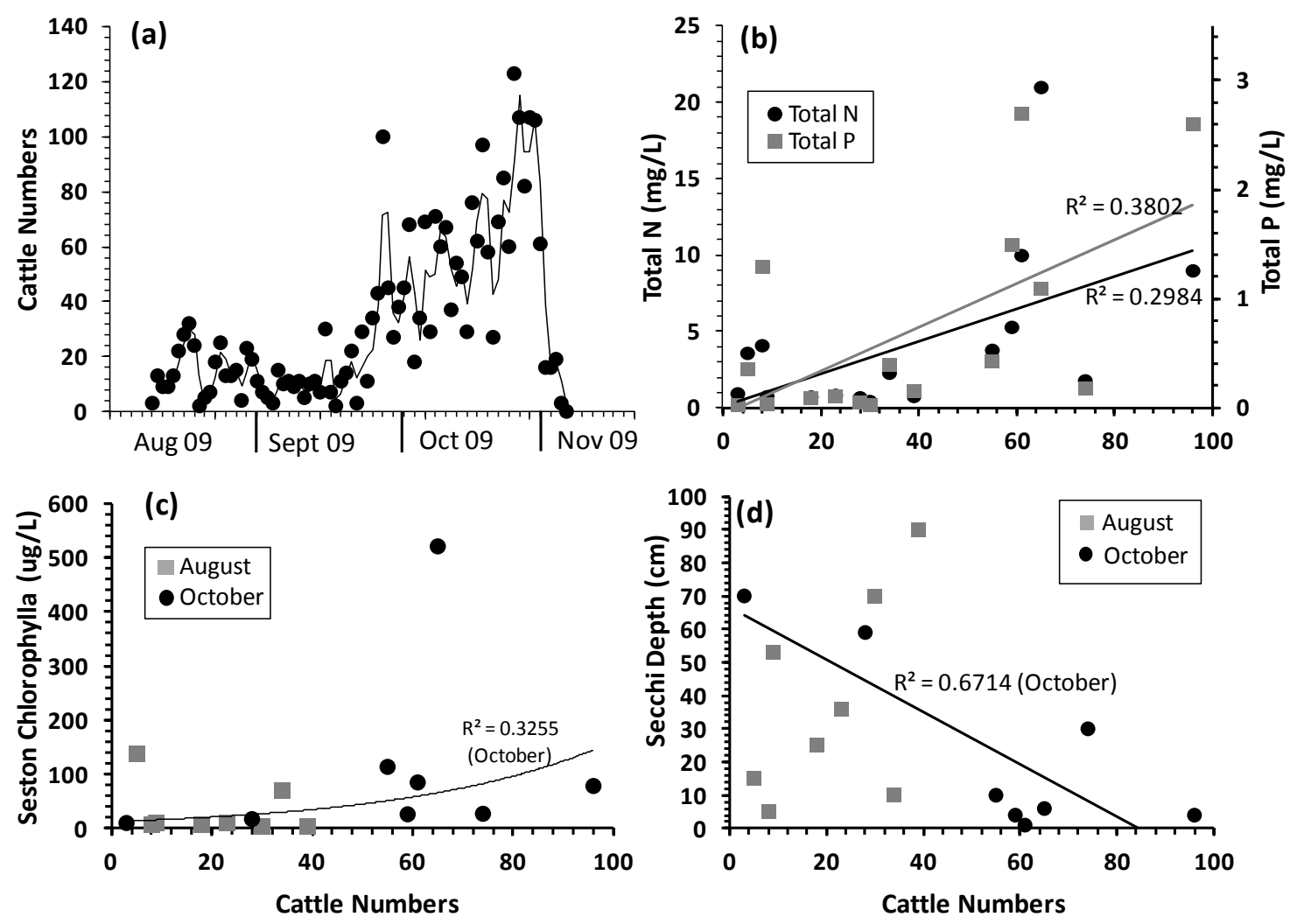

Figure7: 


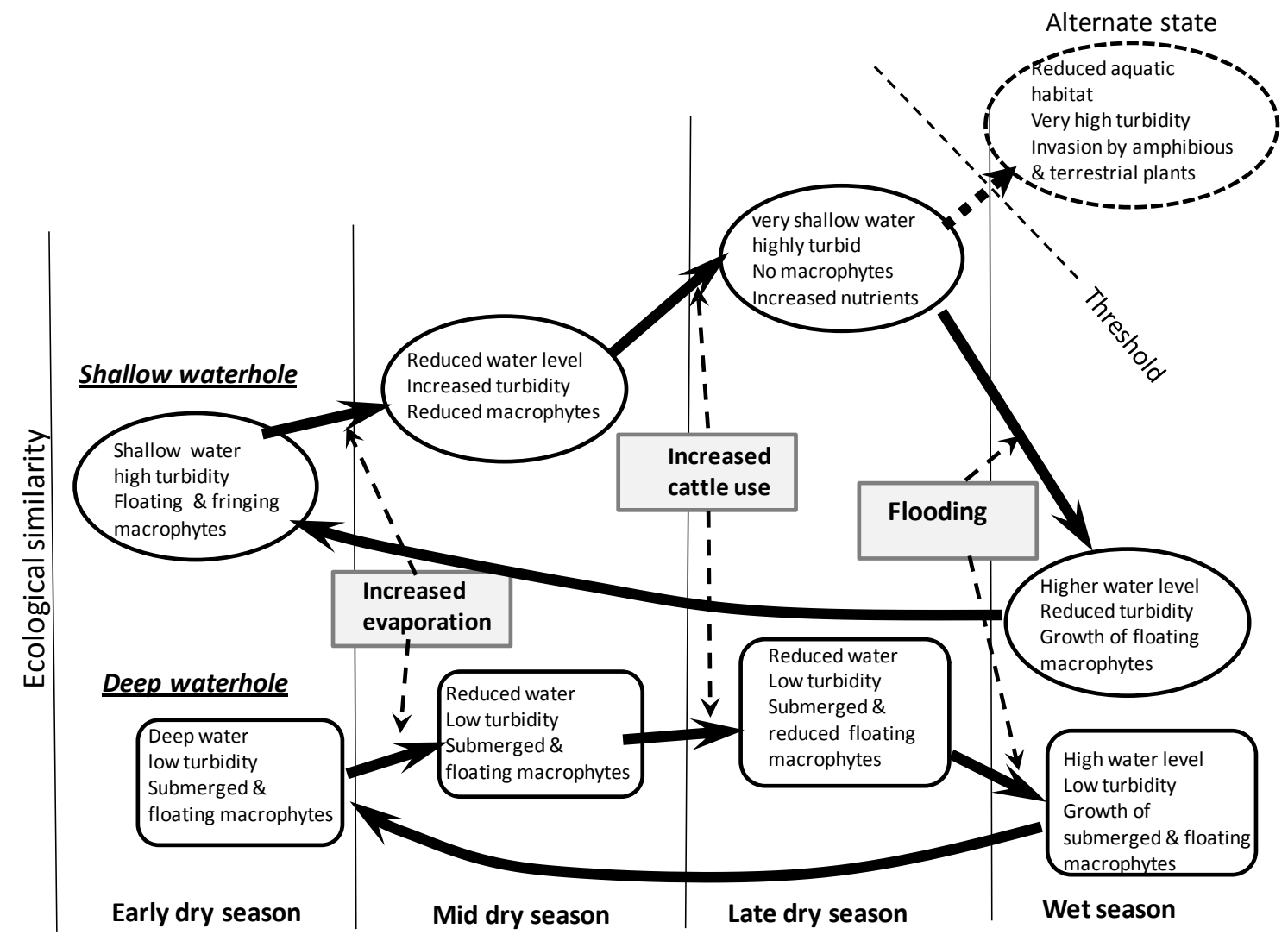

Figure 8: 